\title{
The situation of nursing work and occupational risks from an ergological perspective ${ }^{1}$
}

Rosane Teresinha Fontana²

Liana Lautert ${ }^{3}$

Objective: to understand the work environment according to the concepts, knowledge and values expressed and practiced by nursing professionals in occupational risk management. Methods: this was an ergology-based participant study. Data collection was performed through interviews with key informants and 25 workers, as well as observations and measurements at a Basic Health Unit located in Rio Grande do Sul. Data analysis was based on the Three-Pole Dynamic Device. Results: work conditions were found to be precarious, and workers are exposed to verbal violence and other psychosocial, biological and ergonomic risks. Chemical and physical risks are neglected, and activity is constantly restandardized toward service effectiveness. Conclusion: the studied subjects worked in risky conditions on a daily basis, and this information was expressed through synergistic dialogues and participant observations. Based on the contributions of these individuals, it is possible to merge knowledge obtained from work environments with science in order to address this issue.

Descriptors: Occupational Health; Working Conditions; Occupational Risks.

\footnotetext{
Paper extracted from doctoral dissertation "Nursing work situation in an institution of basic health care: knowledge and practices", presented to Universidade Federal do Rio Grande do Sul, Porto Alegre, RS, Brazil.

${ }^{2} \mathrm{PhD}$, Professor, Universidade Regional Integrada do Alto Uruguai e das Missões, Santo Ângelo, RS, Brazil.

${ }^{3} \mathrm{PhD}$, Associate Professor, Universidade Federal do Rio Grande do Sul, Porto Alegre, RS, Brazil.
}

Corresponding Author:

Rosane Teresinha Fontana

Rua Sete de Setembro, 1126

Bairro: Centro

CEP: 98801-726, Santo Ângelo, RS, Brasil

E-mail: rfontana@urisan.tche.br
Copyright (c) 2013 Revista Latino-Americana de Enfermagem This is an Open Access article distributed under the terms of the Creative Commons Attribution Non-Commercial License (CC BY-NC).

This license lets others distribute, remix, tweak, and build upon your work non-commercially, and although their new works must also acknowledge you and be non-commercial, they don't have to license their derivative works on the same terms. 


\section{Introduction}

Societal changes and new demands have changed the social worlds of work and economics and have raised questions about skills, cultures, obsolescence and illness. In this sense, we can observe workers as they transform prescribed work situations that establish rules and standards in order to combine productivity and body economy.

This is the operational context of ergology, a science that proposes reinterpretations of work and the concepts of action and activity. The ergological method approaches work based on the experience of the person who performs the work, and it analyzes the relationship between the person and the environment ${ }^{(1)}$. Work, according to ergological assumptions, is a human activity situated in time and space that occurs within the process of life ${ }^{(2)}$. Ergology views work as the use of oneself by others and the use of oneself by oneself. Thus, activity is a "drama" of the use of oneself because situations vary depending on the capabilities, resources and selected choices ${ }^{(1)}$. Faced with a lack or deficiency of antecedent norms or prescriptions, the subject needs to renormalize or restandardize, or in other words, to discuss, adapt or change the norms.

Empirically, nursing team workers in many primary health network scenarios can be found working under risky conditions when considering some factors present in this context, such as neglect and impudence by the workers themselves or bad uses of oneself, which are allied with the precarious aspects of the work, the lack of norms and managerial neglect regarding worker health.

However, a discussion of the work conditions associated with nursing, based on the knowledge expressed by individuals who perform the work and focused on occupational risk exposure, could be relevant. This is because such a discussion performs a legitimate diagnosis of the health-disease-work process according to a synergistic dialogue with the protagonists and obtains elements for an intervention intended to improve the worker's quality of life.

In ergology, technical rationality is not sufficient; it is also necessary to consider the rationality of the actual worker activity ${ }^{(1)}$. It is thought that restricting technical analyses to occupational risks while ignoring other involved dimensions will not lead to a complete understanding of the work process, thus justifying the study from this perspective.

According to the Pan American Health

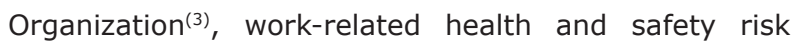

factors can be grouped into the following 5 major groups: physical, biological, chemical, mechanical and accident, ergonomic and psychosocial.

The objective of this study is to understand the work situation in nursing according to the concepts, knowledge and values expressed and practiced by nursing professionals in order to manage occupational risk from an ergological perspective.

\section{Methods}

This is a participant study based on an ergological, theoretical and methodological framework. The participant study method enabled the application of the Three-Pole Dynamic Device (TPDD) that was recommended by Schwartz ${ }^{(1)}$ to combine scientific/ disciplinary knowledge, which is required to establish health conditions and worker and user health protections, and experiential knowledge, which originates from the activity, in order to synergize them in the production of new knowledge.

The study included 25 professionals, 24 nursing technicians/assistants and 1 nurse, who met the established criteria, namely being a member of the nursing team and being in active service. Of these subjects, $72 \%$ had worked for 6 to 10 years in the service and 52\% worked double shifts that were distributed between 2 health institutions and/or studies. The duration of nursing service of studied workers ranged from 5 to 25 years.

The study field was a primary health care service located in a countryside municipality in the state of Rio Grande do Sul, and this service represented the largest local basic unit. This service could be classified, according to Resolution No. 50 of the Board of Directors (Resolução da Diretoria Colegiada; RDC) ${ }^{(4)}$, as a service for the elective outpatient provision of health promotion and care during outpatient and day hospital regimen, as well as a service that provides immediate health care.

Data were collected from June to December 2010 through interviews with key informants and workers, as well as systematic participant observations and measurements of overload, thermal comfort and physical area noise and illumination, which were performed by a work environment engineer. Participant observations occurred in the mornings and afternoons of a 6-day period during randomly selected average periods of 1 $\mathrm{h}$ and $30 \mathrm{~min}$. For the systematic observation Norm no. $32^{(5)}$, the adapted criteria focused on biological, chemical, physical, ergonomic and waste handling risks, as well as those associated with sanitary conditions. 
Items that allowed psychosocial risks to be observed were included in the protocol, according to the classification proposed by the Pan American Health Organization and the Ministry of Health. A micro-recorder and field diary were used to record information.

The information collected through observations, interviews and expert opinions were submitted to content analysis according to a thematic modality. The analysis was based on the TPDD ${ }^{(1)}$. This method of work analysis allows experiential and scientific knowledge to be merged. It is notable that the poles are not mutually exclusive, but are instead complementary and circulate in motions of mutual requests and eventual reworkings of the discipline of origin.

The model proposed by Schwartz was applied(1), thus establishing Pole 1 as the disciplinary knowledge from the fields of health, education, law, social and communication sciences and ergonomics and ergology, the latter being the guiding thread of the study. Pole II covered activity-associated knowledge in terms of the experiences, histories and values of the individuals who experience nursing team work. It is acknowledged that "knowing what lurks within an activity is a type of knowledge that must be developed in order to assess its degree of generality [...]." Thus, this knowledge should not be confused with 'sub-knowledge', and it is essential that one knows and recognizes the disciplinary knowledge that circulates and that can be recreated while performing the activity ${ }^{(1)}$.

In Pole III, the knowledge derived from work situations was merged with science to form proposals for a healthy working environment; these were circumscribed by learning and entrepreneurial learning, a form of humility regarding the work activity that leads to the stripping back of intellectual rationality and intellectual discomfort to comprise a pole for the common world, built from ethics and epistemics ${ }^{(1)}$. The TPDD is therefore the intersection where divisions are broken.

A preliminary analysis of the data (interviews, observations and expert opinions) was presented for discussion and validation. For this purpose, all study participants were invited to a group meeting that was attended by 15 subjects. The aim of this meeting was to validate the data and, from a collective discussion of the data, to build new knowledge that would be represented by proposals for improving the work climate/situation.

The project was approved by the Ethics Committee of the Regional University of High Uruguay and Missions (Universidade Regional do Alto Uruguai e das Missões; URI/BR), Santo Ângelo campus under Protocol No.
0033-4/PPH/10 and by the manager of the institution. Those who agreed to participate were asked to sign a Terms of Informed Consent form.

\section{Results}

\section{Work situation conditions and occupational risks}

Pole I of the TPDD was represented by the disciplinary knowledge obtained through systematic participant observations, made by the researcher, and measurements of physical (noise, humidity and temperature/thermal comfort) and ergonomic (illumination) agents, made by a work environment engineer and monitored by the researcher. Disciplinary skills that accounted for the complexity of the studied scenario were required at this stage.

Pole II was represented by knowledge invested in the workers' experiences, while also accounting for the disciplinary knowledge implicit in the historical, political and social context. Pole III represented new knowledge with regard to disease prevention and the promotion of worker health, which was developed during data socialization and discussions with the participants involved in the study.

Observation allowed the researcher to understand that the workers were exposing themselves to occupational risks on a daily basis whenever there was a lack or deficit of norms. Therefore, some mechanisms were used to manage these gaps while aiming to obtain productivity and body economy, or to restandardize the activity. Among other observations, the physical area is an example of this because it falls far short of what the law demands for user and worker safety. The nursing team passes through 5 doors to gain access to the emergency room, the number of staff is inadequate for the workload during periods of higher demand, and the different risks include inadequate lighting, which creating exposure to ergonomic risk.

[...] The team is small, [...] sometimes there are fewer people. One is busy with something, we have to help a patient and we expose ourselves, get him/her into bed, get him/her out of bed, put him/her in a wheel chair. When you have to put someone on a stretcher, it is a sacrifice; back pain is what we feel the most. For about 4 or 5 years, I have had to make an effort to turn the patient, lift the patient (Worker 11).

While in service, nursing technicians routinely prepare dressing packs for users from all over the municipality so that the users can apply the dressings at home. This activity is considered very tiring by the study participants and leads to pain in the arms and spine. 
Your back hurts because no-one can handle this [shows the cervical region] when you are folding the gauze. When there's a lot of material to prepare, we end up our shift stiff, it's neck pain (Worker 6).

The waiting room for diabetes mellitus and/ or systemic arterial hypertension patient care is the same room that provides access for HIV/AIDS users, thus posing a risk of opportunistic infections that could spread to already vulnerable HIV patients. A similar scenario occurs in the hallway that leads to the pediatric immunizations area, which is shared by the waiting room for patients with appointments for different symptoms such productive coughs, thus exposing healthy children to risk. Both users and workers are thus exposed to biological agents.

The physical space is tight, there is no air circulation, you have direct contact with a tuberculosis patient; there is no specific waiting room, you have contact with patients' secretions (Worker 20).

Cleaning, which is performed by a outsourced company, is also deficient and facilitates the spread of dust and microorganisms. Hand hygiene is poor because there are no devices for proper hand washing techniques in any of the rooms.

It is poor, the staff are unqualified, $[\ldots]$, they're not interested in working, they do not see themselves as having important work [...], we depend on them to clean walls, wash floors, clean instruments/equipment. They just do the basics taking out the trash and mopping the area, and this is very stressful, we know it's a service that needs cleaning (Worker 2).

The nursing technician who collects blood in the AIDS treatment and care section is also exposed to risks as she performs her duties in a precarious area without proper safety equipment to assist tuberculosis patients; this type of infection is very frequent in these users and confirms the occupational vulnerability of nursing staff to this disease(6). In all sections, there is a lack of availability of personal protective equipment in terms of quantity, quality and specificity, thus exposing workers to biological, mechanical and accident risks.

It's a fight until we can convince people to provide some appropriate PPE. You have gloves available [...]. Now we have common masks. The $N 95$ mask is not available. We only have the common, ordinary mask (Worker 2).

In the area allocated to the chemical processing of items and materials, there is concomitant drug administration, among other nursing procedures. The handling of chemical products is performed under unsanitary conditions because the area does not have ventilation or proper protective equipment, thus exposing workers to chemical risks, although many workers disregard or do not recognize this.

Chemicals? I don't think so. Only glutaraldehyde, that's the only 1 here and we only use gloves to prepare it; there's no mask. It's kept right there [in the nursing procedure room] and it is only used for a nebulizer; it is a small amount (Worker 11).

One could observe the readiness of the team to meet the health needs of the users. No situations of neglect or lack of politeness by nursing staff when dealing with users were noted; however, in many instances, these workers were targets of embarrassment and verbal assaults, which constitute psychological violence. This psychosocial risk represented the biggest complaint cited by the subjects because it can cause stress or other mental disorders. It is noteworthy that the majority did not report the assaults.

[...]Verbal abuse by people, users, due to ignorance, the type of person that sometimes arrives already stressed [...] they call us a cow, they say: "I'm going to call someone to teach you." I have mental fatigue. I want to be quiet, without talking (Worker 1).

Insecurity and fear are feelings experienced by the subjects in the face of aggression, which arises particularly from psychologically distressed users and prisoners. The lack of security personnel in the service has also been reported as a lack of safety.

[...] They wanted to put 3 prisoners in the room, and I said, "no, it's 1 at a time". They are handcuffed, but they are very agile, and if you have a syringe you have to be careful (Worker 4).

Noise, humidity and ambient temperature were not reported as physical risks, although these were considered by many to be uncomfortable. It is appropriate to note that the physical area allocated for the workers' meals is also precarious. The environment is humid, with a characteristic odor of mold and poor ventilation. The humidity at the time of measurement exceeded $40 \%$ and reached $72 \%$ in some places, thus constituting a very humid environment. The noise levels and temperatures in many areas exceeded legislative standards, according to the work environment engineer's report (expert). The noise levels ranged from 56.1 to $75.4 \mathrm{~dB}(\mathrm{~A})$. The temperatures varied between 15 and $17^{\circ} \mathrm{C}$, which are below the parameters established for thermal comfort(4) and thus constitute a physical risk.

The service in question is deficient in occupational risk prevention practices and has no Occupational Risk Prevention Program. Due to human resources difficulties, the service does not meet the demands of the Occupational Health Program. There is a work safety 
technician, assigned to the department of public works, who seldom intervenes in the health department; there are no meetings, continuing health education programs or alternatives that list occupational risk prevention and control as their agenda, much less worker comanagement.

I'm not sure why there is a health and occupational service. We have nothing, no lectures, nothing. [...] There's no preventative labor gymnastics, preventive massage, nothing. Nothing to listen to, to watch, nothing, not even education (Worker 2).

Another difficulty noted in the service's work organization was a 'lack of a supervisor/coordinator/ site manager', a recurring comment from immunization workers.

[...] There's no boss who can answer questions. We are ill-advised, we have to solve everything, we have to bear all the responsibility alone (Worker 4 ).

From the data, it can be inferred that both good and bad uses of oneself coexist in the service working environment; the bad uses are generally due to difficulties in dealing with health system gaps and a lack/deficiency of norms.

At the meeting to discuss and validate the study data, the workers noted some alternatives for creating a healthy environment. These resulted from the merging of the knowledge invested in the activity and the disciplinary concepts, thus constituting learning and entrepreneurial learning ${ }^{(1)}$.

The workers suggested labor gymnastics programs, a psychology service and health education activities that could be optimized through partnerships with the Regional University, which could also help to develop projects that would improve the unit.

Permanent health education and technical updating workshops were mentioned as worker necessities. The construction of epidemiological indicators and control of workplace accidents and illnesses, generated by training a group of professionals from each section, could increase the health of public servants. Additionally, providing uniforms, N95 masks, goggles, other PPE and lockers would protect the workers from health problems. Some workers expressed concern about non-compliance with NR $32^{(5)}$.

Recommendations for improvements to the furniture, physical area and logistics were cited for proper activity development, as well as changes in the logistics of production of materials for this population. Participants also indicated a need for a telephone operator and for telephone extensions in all sectors of the unit. The maintenance, adaptation and expansion of the physical area appeared to be among the workers' pressing needs. According to the subjects, the nurses repeatedly asked for building maintenance and painting, central sterilization for all posts and other things, but were unsuccessful. Climate control was suggested in all sectors because of the alternating high and low temperatures. The subjects also requested sanitation service staff training and a surveillance service.

The development of a computerized system for the municipality's health care network was mentioned as a strategy to improve organization and flow, reduce work and costs and streamline the care process.

The workers believed that $90 \%$ of their colleagues were committed, but needed a manager to organize the service. The subjects referred to management difficulties that caused problems of all types. They requested a leader who would be responsible for the service, a general unit coordinator and a proposed Career and Salary Plan, elements that would contribute to the organization and regulation of labor relationships.

\section{Discussion}

In every activity, there is a dynamic into which disruptions and discontinuities are introduced that require the worker to make constant restandardizations regarding the creation of new norms for the performance of his/her task ${ }^{(7)}$. Each day, the worker weaves his/her activity in an intersection between the 'weft', or technical and organizational knowledge tools and users, and the 'warp', the person's own history, with a body that learns and grows older along with his/her values, knowledge and desires ${ }^{(1)}$. It can be difficult to establish health work competencies because the subject is complex, the work situations are difficult to standardize and the care process involves eternally singular encounters between people(8).

Antecedent norms, which the individual can restandardize, almost always exist before the activity and are often prepared by experts with characteristics that are different from the uniqueness of the users for whom the norms are intended. It is known that, to work, the subject requires antecedent norms, which in this study are characterized by manuals, technical notes, prescriptions and standardized procedures. However, it is possible to recreate, reinterpret and develop those norms as a singular activity through successive restandardizations, thus constructing an environment that belongs to oneself $f^{(9)}$ and allowing activity ownership by the worker and body economy. 
However, the choice to transgress from the norm can impose responsibilities on those who work, due to the risks that micromanagement can introduce to the work process. Additionally, the 'secret' of uses of oneself might place the worker in solitude. Thus, it is necessary to publicize the technical act of use of oneself because this attitude confers recognition upon the subject's skill and his/her inventiveness ${ }^{(10)}$. However, attention should be paid to contraventions of norms that involve bad uses of oneself because contraventions can induce colleagues and become catastrophic when an individual change in work method is significant to the collective.

Work in this context constitutes an industrious activity in the sense of mastery and skill(9) in the management of one's own performance. For ergology, this supposes a constant debate between norms that "go beyond the work environment, but lie within the work environment"(11).

The antecedent norm, Ordinance $500^{(12)}$ of the State of Rio Grande do Sul, prescribes that medical item processing sites must provide equipment for the cleaning, disinfection or sterilization of materials. Resolution no. $42^{(13)}$ establishes the mandatory provision of alcohol for hand antisepsis by health services. According to the RDC50(5), the physical area for AIDS outpatient care should include an individual inhalation room for treatment, and there are regulatory standards ${ }^{(4)}$ that make it compulsory for employers to provide PPE; these were missing elements in the field under study.

The service's disengagement with and disrespect of worker protections in the workplace is a demotivating and unsettling factor that leads to a greater likelihood of mistakes and accidents. Thus, management and organizational practices have significant effects on the healthiness of the work environment ${ }^{(14)}$.

Regarding the lack/deficiency of norms, it is worth noting that, while antecedent norms are valued, "they fall short due to a lack of other important factors for job viability that allow the achievement of health, ways of doing things and the conditions for doing so"(15). Thus, there may be a sort of weakening of the possibility of environmental (re) creation that is established by the work organization and offered conditions.

Among other things, these norms were not fully met in the studied field due to difficulties in micromanagement - management of oneself and of the environment by the workers - that were caused by difficulties in macromanagement adherence. It should be noted that micromanagement exists in all work because "in the space between the work prescribed and actually performed, there is a requirement for micromanagement of the situation and the constant trading of collective exchanges"(7).

Thus, the worker is asked to restandardize in his/ her own way to make work possible, while making some bad uses of oneself. "Everyone seeks in their work a balance between the use of oneself that is requested and that which is consented. Failure is painful $[. .$.$] the$ drama can become tragic, leading to great suffering [...] "(1), such as in the phenomenon of psychological violence. The worker is constantly called upon to address situations of psychological aggression. The pressure experienced by workers and the consequent exposure to violence, arising from users, also creates a drama with regard to the uses of oneself by themselves and by others in that it requires mobilization of the body-self to face unusual situations.

The same goes for the lack of nurses needed to supervise all of the units. Resolution No. 302 of the Federal Council of Nursing(16) states that all establishments in which nursing activities occur must submit a Certificate of Technical Responsibility of Nursing, which is completed by a nurse. In this case, it constitutes a lack/deficiency of norms that is difficult to restandardize. Although ergology advocates People Management, both plural and collective, supervision is requested by the team in order to share the responsibilities and build a channel of communication between the different spheres of public service and to aid in the requesting of measures to ensure health and reduce risks.

There is always an engagement of the body-self in work, and thus some risk is inevitable and is not solely the responsibility of the activity protagonists, considering that, in a work situation, this is not possible due to the relationship between autonomy and heteronomy and also to the subordinate relationship of workers to employers ${ }^{(17)}$.

Repetitive Strain Injuries (RSI) and Work-Related Musculoskeletal Disorders (WMSDs), which were cited by the workers, are multifactorial(18). These transform work into suffering, which extends into the rest period because symptom onset occurs during peak production and at the end of the working day, thus requiring the worker to rest the affected area at night, while at home.

A study that evaluated the association between musculoskeletal pain intensity and the ability to work in nursing professionals identified that ratings of severe pain and unbearable pain were positively associated with a reduced ability to work ${ }^{(19)}$. That result confirms the 
influences of this type of injury on both worker health and the quality of the work process ${ }^{(19)}$.

Another issue discussed by the workers was physical risk. The antecedent norm, or NR $17^{(4)}$, requires temperatures of $20-23^{\circ} \mathrm{C}$ for thermal comfort and noise levels between 30-55 $\mathrm{dB}(\mathrm{A})$ for acoustic comfort(20), parameters that were not observed in this service.

Together with the worker that uses oneself, restandardizes and makes his/her activity possible through micromanagement, it is possible to wonder about the effective adherence of 'macro and mesomanagement' in the workplace and the co-management of all that contributes to health in this area.

Collective strategies to prevent harm and health risks should aim to improve work organizations and involve the provision of a safe environment and materials for activity development, the implementation of educational programs and an awareness of behavioral changes by both workers and managers ${ }^{(21)}$. The latter is essential for the environment to develop in a way that adds value and attention to the caregivers and service users.

\section{Conclusion}

The studied service nursing team experienced some occupational risks in their daily work that were expressed through synergistic dialogues and participant observations. The occupational risks that caused the greatest subject exposure to suffering and physical and mental illnesses were psychosocial risks, which were characterized by verbal abuse and a lack of security. The subjects also expressed distress with regard to the precariousness of the service, specifically a lack of adequate materials and facilities, which was a situation that caused worker embarrassment when it led to poor quality work.

Profound insights on work conditions and risk exposure on the basis of studies in primary health units are imperative for all system managers, from micro to macrospace, who aim to propose alternatives to minimize suffering at work.

Effectiveness and efficiency, which are associated with access to and improvements of the health system, and cross-disciplinary knowledge are key to addressing this critical problem in public health service provision. For the population, educational campaigns about the health system are imperative to an understanding of the dynamics of this network and the valuation of public servants.

\section{References}

1. Schwartz Y, Durrive L. Trabalho e Ergologia: conversas sobre a atividade humana. Niterói: Ed UFF; 2007.

2. Borges MES. Trabalho e gestão de si: para além dos "recursos humanos". Cad Psicol Soc Trab. [Internet]. 2004 [acesso 27 mar 2010]; 7:41-9. Disponível em: http://www.revistasusp.sibi.usp.br/scielo.

3. Organização Pan-Americana da Saúde no Brasil. Ministério da Saúde do Brasil (BR). Doenças relacionadas ao trabalho: manual de procedimentos para os serviços de saúde. Brasília (DF): Ministério da Saúde do Brasil; 2001.

4. Ministério da Saúde (BR). Agência Nacional de Vigilância Sanitária. Resolução RDC n. ${ }^{\circ} 50$, de 21 de fevereiro de 2002. Dispõe sobre o regulamento Técnico para planejamento, programação, elaboração e avaliação de projetos físicos de estabelecimento assistenciais de saúde [Internet]. Brasília (DF); 2002 [acesso 23 abr 2011]. Disponível em: http://www.anvisa.gov.br/legis/ resol/2002/50_02rdc.pdf.

5. Ministério do Trabalho e Emprego (BR). Normas Regulamentadoras. [Internet]. Brasília (DF): 1978 [acesso 15 ago 2009]. Disponível em: http://portal.mte. gov.br/legislacao/normas-regulamentadoras-1.htm.

6. Souza JN, Bertolozzi MR. The vulnerability of nursing workers to tuberculosis in a teaching hospital. Rev. Latino-Am. Enfermagem. 2007;15(2):259-66.

7. Silva NM, Muniz HP. Vivências de trabalhadores em contexto de precarização: um estudo de caso em serviço de emergência de hospital universitário. Estud Pesqui Psicol. 2011;11(3):821-40.

8. Scherer MDA, Pires D, Schwartz Y. Trabalho coletivo: um desafio para a gestão em saúde. Rev Saúde Pública. 2009;43(4):721-25.

9. Schwartz Y, Durrive L. Glossário da ergologia. Laboreal [Internet]. 2008 [acesso 20 jan 2009];4(1):23-8. Disponível em: http://laboreal.up.pt/revista/artigo.php. 10. Fonseca TMG, Barros ME. Entre prescrições e singularizações: o trabalho em vias da criação. Fractal Rev Psicol. 2010; 22(1):101-14.

11. Schwartz Y. Entrevista com Yves Schwartz. Trab Educ Saúde 2006;4(2):457-66.

12. Secretaria de Saúde do Estado do Rio Grande do Sul (BR). Portaria 500 de 31 de agosto de 2010. Regulamento técnico para Processamento de artigos por método físico em estabelecimentos sujeitos à Vigilância Sanitária no RS [Internet]. Porto Alegre (RS); 2010 [acesso 16 mai 2011]. Disponível em: http://www.osap.org/resource/ resmgr/Docs/PORTARIA_500_31_AGOSTO_2010.pdf 
13. Ministério da Saúde (BR). Agencia Nacional de Vigilância Sanitária. Resolução da Diretoria Colegiada n. 42, de 25 de outubro de 2010. Dispõe sobre a obrigatoriedade de disponibilização de preparação alcoólica para fricção antisséptica das mãos, pelos serviços de saúde do País [Internet]. Brasília; 2010 [acesso 24 nov 2010]. Disponível em:ftp://ftp.saude. sp.gov.br/ftpsessp/bibliote/informe_eletronico/2010/iels. out.10/Iels203/URS-MS-ANVISA-RDC-42_251010.pdf

14. Neves HCC, Souza ACS, Medeiros Marcelo, Munari DB, Ribeiro LCM, Tipple AFV. Safety of Nursing Staff and Determinants of Adherence to Personal

Protective Equipment. Rev. Latino-Am. Enfermagem. 2011;19(2):354-61.

15. Masson LP, Brito JC, Sousa RNP. O trabalho e a saúde de cuidadores de adolescentes com deficiência: uma aproximação a partir do ponto de vista da atividade. Saúde Soc 2008;17(4):68-80.

16. Conselho Federal de Enfermagem (BR). Resolução No 302 de 16 de março de 2005. Aborda a responsabilidade técnica do enfermeiro. Rio de Janeiro; 2005.

17. Nouroudine A. Risco e atividades humanas acerca da possível positividade aí presente. In: Athayde M, Brito J, Alvarez D, Organizadores. Labirintos do Trabalho: interrogações e olhares sobre o trabalho vivo. Rio de Janeiro: DP\&A; 2004. p. 37-62.

18. Ministério da Saúde (BR). Instrução normativa INSS/ DC n॰ 98, de 05 de dezembro de 2003. Aprova Norma Técnica sobre Lesões por Esforços Repetitivos - LER ou Distúrbios Osteomusculares Relacionados ao TrabalhoDORT. Brasília (DF): Ministério da Saúde; 2003.

19. MagnagoTSBS, Lima ACS, Prochnow A, Ceron MDS, Tavares JP, Urbanetto JS. Intensity of musculoskeletal pain and (in) ability to work in nursing. Rev. Latino-Am. Enfermagem. 2012;20(6):1125-33.

20. Associação Brasileira de Normas Técnicas. NBR 10152. Níveis de ruído para conforto acústico. Rio de Janeiro: ABNT; 1987.

21. Vieira M, Padilha MI, Pinheiro RDC. Analysis of Accidents with Organic Material in Health Workers. Rev. Latino-Am. Enfermagem. 2011;19(2):332-9. 